\title{
MANAJEMEN PEMASARAN HOTEL SYARIAH DENGAN PENDEKATAN MAQASHID SYARIAH (Studi Pada Hotel Syariah di Solo)
}

\author{
Azidni Rofiqo \\ University of Darussalam Gontor \\ Email : rofiqozidni@gmail.com
}

\begin{abstract}
The purpose of this study is to look at sharia business management (Syariah Hotel Solo) with the maqoshid Syariah approach. Maqoshid sharia is the right measurement tool to see the success of a religion-based business. The research method used is qualitative with the approach of maqoshid sharia. The analysis used is descriptive analysis. The data used are primary and secondary data. The results of this study indicate that Sharia Hotels have implemented maqoshid sharia by showing activities and management in accordance with maqoshid. The limitation of this study is to only use maqoshid syariah descriptively. The suggestion for further research is that research can be developed with hotels based on sharia and can use definite measuring instruments, such as the maqoshid syariah index.
\end{abstract}

Keyword: Syari'ah Hotel, Management, Maqoshid Syari'ah

Abstrak :Tujuan dari penelitian ini adalah melihat manajemen bisnis syariah (Syariah Hotel Solo) dengan pendekatan maqoshid syariah. Maqoshid syariah merupakan alat ukur yang tepat untuk melihat kesyari'ahan dari suatu bisnis yang berbasis agama. Metode penelitian yang digunakan adalah kualitatif dengan pendekatan maqoshid syariah. Analisis yang digunakan adalah deskriptif analisis. Data yang digunakan adalah data primer dan sekunder. Hasil dari penelitian ini menunjukkan bahwa Syariah Hotel telah melaksanakan maqoshid syariah dengan ditunjukkan kegiatan-kegiatan beserta manajemen yang sesuai dengan maqoshid. Keterbatasan penelitian ini adalah hanya menggunakan maqoshid syariah secara deskriptif. Saran untuk penelitian selanjutnya adalah penelitian dapat dikembangkan dengan hotel-hotel yang berlandaskan syariah dan dapat menggunakan alat ukur yang pasti, seperti index maqoshid syariah.

Kata Kunci: Syari'ah Hotel, Manajemen, Maqoshid Syariah.

\section{A. PENDAHULUAN}

Agama Islam adalah agama yang mengatur semua kehidupan manusia. Semua muslim harus patuh dan tunduk pada ajaran syariat Islam. Seorang muslim sangat penting untuk memperhatikan makanan yang akan dimakan. Makanan yang dikonsumsi harus halalan thoyyiban. tidak hanya makanan, tetapi gaya hidup juga hahalan thoyyiban.

Wisatawan pada dekade Januari hingga Agustus 2018 wisatawan mancanegara berjumlah 10,58 juta ${ }^{1}$. Para wisatawan umumnya mencari

${ }^{1}$ https://www.bps.go.id/pressrelease/2018/10 /01/1476/jumlah-kunjungan-wisman-ke-indonesiaagustus-2018-mencapai-1-51-juta-kunjungan-.html kesenangan dengan berbagai hal. Penelitian Garibaldi, et. al, menunjukkan bahwa para mayoritas pelancong berfokus pada hal makanan dan minuman (gastronomi), dan pelancong dari negara barat akan selain mencari makanan dan minuman khas daerah juga minumminuman keras seperti wine, arak dan lainnya $^{2}$ dan makanan yang berbahan daging babi dan yang lainnya.

Para wisatawan yang berkunjung ke Indonesia juga memerlukan tempat singgah, diantaranya adalah hotel.

${ }^{2}$ Roberta Garibaldi, MetthewJ. Stone, Erik Wolf, and Andrea Pozzi, Wine travel in the United States: A Profile of Wine Travellers and Wine Tours,J. Tourism Management Perspective, 23 (2017), hlm. 53-57. 
Manajemen hotel mayoritas akan menuruti permintaan dan keinginan konsumen tanpa melihat halal maupun haram dari permintaan tersebut. Hal tersebut dapat dilihat pada penelitian Baker, bahwa untuk memaksimalkan keuntungan rata-rata hotel akan menyediakan wine dan tempat hiburan ${ }^{3}$.

Hotel adalah sarana menginap dan makan untuk umum. Di dalam hotel biasanya terdapat berbagai macam hiburan, seperti; bar, kolam renang dan lain-lain. Hotel biasanya menyiapkan alkohol dan makanan dengan bahan makanan dari babi, dan makanan lainnya yang sesuai dengan permintaan konsumen ${ }^{4}$. Di beberapa hotel juga tersedia pijat massage, tidak hanya pijat, tetapi terjadi perzinanaan hingga transaksi prostitusi. ${ }^{5}$ Pihak hotel tidak menjamin atas tindakan-tindakan asusila tersebut.

Hotel syariah diharapkan menjadi solusi atas permasalahan yang dihadapi umat Islam, dari makanan dan minuman non halal hingga asusila.

Alserhan dalam penelitiannya mendapati bahwa hotel syariah dalam

3 Baker Ahmad Alserhan et al., 'The transparency of Islamic hotels: "Nice Islam" and the "self-orientalizing" of Muslims?', International Journal of Tourism Research, vol. 20, no. 4 (2018), hlm. 475-87.

${ }^{4}$ Ibid.

${ }^{5}$ http://www.tribunnews.com/regional/2019/ 01/05/kronologi-artis-va-ditangkap-di-hotelprostitusi-online-terungkap-dari-laporan-masyarakat. Diakses: 27 Feb 2019, 13:28 pengelolaan syariah complient mayoritas tidak transparan, artinya mayoritas hotel syariah masih menuruti konsumen yang menginginkan minuman al kohol, makanan haram dan massage non syar' $i^{6}$.

Peluang pasar syari'ah terbuka lebar, pasalnya adalah bahwa umat Islam di dunia berjumlah pada tahun 2018 berjumlah 1,8 milyar orang atau $24,1 \%$ dari penduduk dunia ${ }^{7}$. Negara yang mempunyai potensi pasar syariah terbesar adalah Indonesia, karena Indonesia berpenduduk muslim terbesar yaitu sebanyak $12,7 \%$ dari penduduk muslim dunia, atau sebanyak 204,847,000 orang ${ }^{8}$.

Salah satu bisnis syari'ah yang booming adalah pariwisata syari'ah. Hotel syari'ah dan restoran halal menjadi pendorong utama bagi berkembangnya pariwisata syariah.

Saat ini ukuran syar'i atau tidak suatu bisnis bisa diukur dengan maqoshid syari'ah. Maqoshid syari'ah merupakan konsep penting di dalam menentukuan hukum-hukum Islam. Inti dari teori maqashid al-syari'ah adalah untuk mewujudkan kebaikan sekaligus menghindarkan keburukan, atau menarik manfaat dan menolak madharat. Istilah

\footnotetext{
6 Alserhan et al., 'The transparency of Islamic hotels: "Nice Islam" and the "selforientalizing" of Muslims?'

${ }^{7}$ http://www.pewresearch.org/facttank/2017/04/05/christians-remain-worlds-largestreligious-group-but-they-are-declining-in-europe/

${ }^{8}$ Sensus Penduduk 2010. Jakarta, Indonesia: Badan Pusat Statistik. 15 May 2010.
} 
yang sepadan dengan inti dari maqashid al-syari'ah tersebut adalah maslahat, karena penetapan hukum dalam Islam harus bermuara kepada maslahat ${ }^{9}$.

$$
\text { Urgensi maqoshid syariah }
$$

didasarkan pada beberapa pertimbangan, diantaranya adalah; hukum Islam adalah hukum yang bersumber dari wahyu Tuhan dan diperuntukkan bagi umat manusia. Oleh karena itu, ia akan selalu berhadapan dengan perubahan social (termasuk bisnis hotel syariah). Untuk menyelaraskan hal tersebut maka diperlukan teori maqoshid syari' $a h^{10}$.

Ta'lil syari'at atau ditetapkannya syariat itu adalah untuk kemashlahatan dari manusia itu sendiri ${ }^{11}$. Mashlahah merupakan manfaat yang dituju oleh Syari' untuk hamba-hambanya dalam menjaga agama, jiwa, akal, keturunan, harta. Oleh karena itu tujuan syariah yang paling pokok ada 5 yaitu; hifdzu ad din, hifdzu nafs, hifdzu 'aql, hifdzu nasl dan hifdzu maal $^{12}$.

Selanjutnya al-Buthi menjelaskan bahwa tidak dipertentangkan secara fitrah manusia motif dari semua perbuatan dan

${ }^{9}$ Ahcene Lahsasna, Maqashid al-Shari'ah, (Kuala Lumpur, IBFIM, 2013), hal. 39. Ghofar Shidiq et al., Maqashid al-syari'ah, Sultan Agung Vol Xliv No. 120118 Juni - Agustus 2009, hlm. 117-30.

${ }^{10}$ Lahsasna.Maqoshid..., hlm. 124

${ }^{11}$ Moh. Toriquddin, Teori Maqoshid Syari'ah menurut Imam Syatibi, de Jure, Jurnal Syari' ah dan Hukum, Vol. 06, No. 01, 2014, hlm. 3347

${ }^{12}$ Ahmad Ar Raisuni, Nadzoriyyatu Maqoshid inda Imam As Syatibi, (Virginia: International of Islamic Thought, 1995), hlm. 336 pekerjaan secara keseluruhan adalah untuk mendapatkan kemanfaatan bagi diri secara khusus maupun bagi orang lain secara umum. Islam adalah agama fitrah yang mana Allah menetapkan hukum-hukum adalah untuk kemanfaatan hamba. Fitrah juga sebagai dasar untuk semua akhlak dan keutamaan bagi hambanya ${ }^{13}$.

Menurut As Syatibi, adanya ikatan hukum sebenarnya bertujuan untuk menjaga tujuan (maqoshid)hukum pada diri hamba. 3 macam maqoshid; dhoruriyat, hajiyat, tahsiniat ${ }^{14}$. Atau dalam masyarakat biasa disebut; kebutuhan primer, sekunder, dan tersier.

Musthafa Omer Muhammed (2008) "The Performance Measures of Islamic Banking Based on The Maqashid Framework". Hasil penelitian ini menghimbau kepada perbankan syariah untuk menggunakan pedoman maqashid syari'ah sebagai kinerja perbankan dalam rangka menciptakan pengembangan kesejahteraan masyarakat yang tepat ${ }^{15}$.

Syafi'i Antonio, et. al. (2012) Dalam penelitiannya yang berjudul "An Analysis of Islamic Banking Performance: Maqashid Index Implementation in Indonesia and Jordania”. Penelitian ini

${ }^{13}$ Muhammad Said Ramdan al-Butiy, Dawabit al-Maslahat fi al-Syarīah al-Islamiyyah, (Beirut: Muassasah al-Risalah, 2001), hlm. 27.

14 Ahmad Ar Raisuni, Nadzoriyatu Maqoshid..., hlm. 117

${ }^{15}$ Mustafa Omar Mohammed and Dzuljastri Abdul Razak, 'The Performance Measures of Islamic Banking Based on th Maqashid Framework e, IIUM International Accounting Conference (INTAC IV), no. June (2008), hlm. 1-17. 
mengukur kinerja bank syariah di Indonesia dan di Yordan dengan menggunakan index maqoshid syari'ah. Penelitian ini mengandung kebaruan bahwa mengukur kinerja tidak hanya dengan pendekatan rasio keuangan tetapi lebih tepat dengan menggunakan index maqoshid syariah ${ }^{16}$.

Hotel syariah adalah penginapan yang diperuntukkan bagi para tamu dengan menjalankan aturan-aturan Islam. Dengan demikian segala manajemen tata kelola hotel syari'ah harus sesuai dengan maqoshid syariah itu sendiri. Artikel ini membahas manajemen hotel syariah dengan pendekatan maqoshid syari'ah.

\section{B. METODE PENELITIAN}

Menjawab rumusan masalah dengan menggunakan pendekatan kualitatif. Dalam penelitian ini, metodologi yang digunakan agar dapat ditemukan deskripsi yang mendalam, dan mampu memahami maknanya. Pendekatan kualitatif dengan maqoshid syari'ah.

Mengacu pada rumusan masalah dalam penelitian ditujukan pada pihak manajemen perhotelan syariah dalam meningkatkan kesejahteraan konsumen, maker decition, maupun karyawan yang berdasarkan maqashid syari'ah yang mencakup hifzu al-din, hifzu al- 'aql,

${ }^{16}$ Muhammad Syafii, Yulizar D. Sanrego, and Muhammad Taufiq, 'An Analysis of Islamic Banking Performance: Maqashid Index Implementation in Indonesia and Jordania', Journal of Islamic Finance, vol. 1, no. 1 (2012), hlm. 12-29. hifzu al-nafs, hifzu al-nasl, dan hifzu almal sebagai model manajemen perhotelan syariah yang mampu meningkatkan kesejahteraan sosial.

Sumber data, data primer yang berasal dari wawancara mendalam dan observasi langsung di lapangan. Di dukung dengan data sekunder yang diperoleh dari dokumen atau laporan relevan. Pengumpulan data dalam penelitian ini menggunakan wawancara, observasi dan dokumentasi. Adapun analisis data menggunakan teknik reduksi data, display data dan verifikasi data. Uji keabsahan data meliputi: uji kredibilitas (teknik perpanjangan keikutsertaan, ketekunann pengamatan, triangulasi, diskusi dengan teman sejawat), uji transferbilitas (kepastian data dengan rinci), uji dependabilitas dengan mengaudit proses penelitian dan uji konformalitas menguji hasil penelitian (kepastian data) untuk menarik kesimpulan.

\section{HASIL DAN PEMBAHASAN}

Syariah Hotel Solo adalah bagian dari Lor In Hotel Solo yang dibangun satu lokasi yang sama yang beralamatkan Jln. Adi Sucipto No 47, Desa Gonilan, Kecamatan Kartasura, Sukoharjo, adalah bagian dari karesidenan Kota Solo. Luas hotel tersebut $6 \mathrm{Ha}^{2}$. Letaknya strategis dekat dengan bandara internasional Adi Sumarmo dengan jarak $5 \mathrm{KM}$ dengan 
jarak tempuh \pm 10 menit, dan juga dekat dengan pusat bisnis kota Solo, seperti mall, yang kurang lebih $5 \mathrm{KM}$ atau jarak tempuh \pm 10 Menit $^{17}$.

Syariah Hotel Solo ini memiliki wilayah perbatasan antara Solo, Karanganyar, Sukoharjo, dan Boyolali. Selatan berbatasan dengan Kabupaten Wonogiri, timur berbatasan dengan Kabupaten Karanganyar, utara berbatasan dengan Kota Solo dan Kabupaten Boyolali. Barat berbatasan dengan Kabupaten Sukoharja dan Kabupaten Klaten $^{18}$. Letak yang strategis ini menjadi kekuatan bagi Syariah Hotel Solo, yang mana hal tersebut salah satu pertimbangan calon tamu untuk memilih Syariah Hotel Solo berdasarkan lokasi.

Visi Syariah Hotel Solo. Menjadi Hotel Syariah berbintang pertama di Surakarta dan Jawa Tengah yang paling diminati konsumen dan mendapatkan keuntungan secara signifikan dalam lima tahun kedepan ${ }^{19}$.

Misi, Berkomitmen untuk menghasilkan keuntungan optimal kepada pemilik. Memenuhi dan meningkatkan kebutuhan konsumen dan pemilih hotel dengan memberikan produk dan pelayanan yang prima. Berkomitmen

${ }^{17}$ http://www.syariahhotelsolo.com/ diakses pada hari Sabtu, 2 Maret 2019 Pukul 06.30

${ }^{18}$ Diskominfo, Pariwisata dan Budaya, edisi VIII, (Solo, Dinas Pariwisata dan Budaya, 2014)

${ }^{19}$ Hasil Observasi di Syariah Hotel Solo, pada tanggal 13 Oktober 2018 untuk menjadi hotel dengan branding yang dikenal oleh konsumen baik nasional maupun internasional ${ }^{20}$.

Fasilitas Syariah Hotel, Security office,Parking area, CCTV, Wifi gratis, Smoking area, 24 jam room service, Laundry service, Lift, Layanan antarjemput bandara dengan biaya tambahan dan layanan antar- jemput gratis ke pusat kota Solo, Mushola disetiap lantai, Alat penanda waktu shalat, Rest room.

Fasilitas Kamar, fasilitas kamar yang komplit yakni AC, TV, face towel, hand towel, body towel, coffee and tea maker, table, chair, bathroom dilengkapi amenities, brankas, line internet, mini bar, telephone, shower, slipper dan room stationary, Al- Quran, mukenah dan sajadah untuk kebutuhan rohani.

Fasilitas Food and Beverage, Syariah Hotel Solo mempunyai fasilitas penyediaan makanan dan minuman yaitu AL Kautsar Coffe Shop and Restaurant. AL Kautsar Coffe Shop and Restaurant Syariah Hotel Solo merupakan restaurant hotel pertama di Jawa Tengah yang mendapatkan sertifikat halal dari LPPOM MUI Jateng, yang menjamin semua makanan dan minuman yang disajikan halal. Restaurant yang berada di lantai satu, bersebelahan dengan lobby akan memenuhi kebutuhan makan pagi, siang dan makan malam tamu. Tidak hanya 
menu local dan nusantara yang ditawarkan, tersedia juga menu Eropa sampai dengan menu Timur Tengah.

Produk yang ditawarkan, sudah dicek kualitas kehalalan dan segi baiknya produk tersebut, malalui bagian syariah. Syariah Hotel Solo merupakan satusatunya hotel yang memenuhi 11 kriteria kehalalan MUI, seperti tingkat kritis bahan pangan, daftar produk dan bahan pangan, SOP pembelian dan analisa pangan dan lainnya. Syariah Hotel Solo juga menjadi satu-satunya hotel di Jawa Tengah yang pelayanannya memenuhi standar Dewan Syariah Nasional, terutama di sisi restoran ${ }^{21}$.

Untuk memuaskan para tamu, manajemen Syariah Hotel Solo menerapkan komunikasi yang super cepat dan baik, misalkan, bagian F\&B dengan bagian receptionis dan bagian house keeping. Bagian front office dengan bagian accounting, dan lain-lain. Hal ini terbentuk karena budaya kerja yang efektif dan efisien, hal ini mendorong terjadinya integritas antar bagian dan menjadikan antar bagian menjadi solid. Selain itu para karyawannya diberikan pelatihan supaya menjadi profesional dan akhirnya dapat memuaskan para tamu hotel $^{22}$.

${ }^{21}$ Wawancara dengan Manager System Jaminan Halal Syariah Hotel Solo, bapak Yanuar Fahmi, 13 Oktober 2018, pukul 13.00-14.00

${ }^{22}$ Ibid.,
Logistik kedalam, Syariah Hotel Solo memiliki quality control, yang secara spesifik melakukan pengecekan, dan menyeleksi barang atau bahan baku yang dibutuhkan oleh Syariah Hotel Solo , barang yang masuk harus melalui qualty control untuk memastikan kualitas dan kuantitas barang yang masuk, supaya sesuai dengan yang diinginkan dan dibutuhkan oleh Syariah Hotel Solo . Bahan yang dikirim oleh suplyer ditangani oleh bagian yang berwenang, dan disetorkan ke gudang, barang yang datang langsung ditangani oleh bagian gudang yang lantas diperiksa oleh bagian gudang dan quality control. Barang yang datang harus berupa barang yang halal dan baik. barang tersebut diperiksa kehalalan dan kebaikannya melalui bagian keagamaan dan keruhanian Syariah Hotel Solo. Barang-barang yang tidak sesuai keinginan lantas dilaporkan ke suplyer untuk diambil kembali ${ }^{23}$.

SOP pelayanan tamu, Pelayanan yang prima dan service yang memuaskan merupakan hal yang mutlak dikerjakan oleh para pegawai Syariah Hotel Solo . Untuk menjaga reputasi pelayanan, Syariah Hotel Solo menerapkan SOP 5 S, yaitu Senyum, Sapa, Salam, Sopan, dan Santun. Selain itu, Syariah Hotel Solo juga menyediakan. quistioner kepuasan, dan juga kritik dan saran kepada para 
tamu, sebagai bahan evaluasi pihak manajemen Syariah Hotel Solo untuk meningkatkan kualitas layanan Syari'ah Hotel $^{24}$.

Selain itu, para karyawan memastikan bahwa tamu yang berlainan jenais merupakan mahromnya ${ }^{25}$.

Dari observasi peneliti, didapatkan bahwa para pegawai di Syariah Hotel Solo ini sangat solid, senyum dan sapa ketika bertemu, salam ketika bertemu, santun dalam berucap, sopan dan syar'i dalam memakai pakaian. Para pekerja diberi pelatihan supaya menjadi pekerja yang profesional di dalam melayani para $\operatorname{tamu}^{26}$

Prinsip amanah dalam pelayanan di Syariah Hotel Solo sangat dikedepankan. Semua staf di seluruh bagian harus jujur dan amanah, jika kedapatan salah satu pekerja yang tidak jujur dan amanah maka dikenakan sanksi yang berupa surat peringatan hingga pemecatan ${ }^{27}$.

Selain itu, pelayanan juga berupa ceramah agama pada waktu-waktu tertentu, para tamu disuguhi dengan pengajian oleh beberapa ustadz yang kredibel dan berpengalaman ${ }^{28}$.

${ }^{24}$ Hasil wawancara dengan kepala bagian HRD pada tanggal 13 Oktober 2018 pukul 10.1511.30 .

${ }^{25}$ Ibid.

${ }^{26}$ Observasi di Syari'ah Hotel Solo, pada tanggal 13 Oktober 2018.

${ }^{27}$ Hasil wawancara dengan kepala bagian HRD pada tanggal 13 Oktober 2018 pukul 10.1511.30 .

$$
{ }^{28} \text { Ibid }
$$

Sumber Daya Manusia, Di dalam rekrutmen karyawan Syariah Hotel Solo , maka HR Manajer menyeleksi berdasarkan kriteria, yaitu; beragama Islam, sehat jasmani dan rohani, memiliki akhlaqul karimah, memiliki skill yang standard hotel Syariah, mempunyai integritas tinggi, disiplin, berpenampilan rapi dan bersih, ramah dan tanggung jawab, serta ahli dibidangnya. Selain tersebut, peraturan bagi karyawan di Syariah Hotel Solo adalah menjalankan syari'at Islam. Jika kedapatan karyawan tersebut melanggar syariah misalkan; berzina, berjudi, minuman keras, narkoba, maka pihak manajemen akan mengeluarkannya secara tidak hormat $(\text { pecat })^{29}$.

Dalam membina para karyawan, pihak manajemen mengadakan pelatihan keprofesionalan pekerja setiap 4 bulan sekali. Selain itu, setiap pagi semua karyawan mengadakan morning meeting dengan membaca ayat suci al-Qur'an, ma'tsurat, ceramah dari ustadz dan doa. Di dalam morning meeting para manajer mengadakan evaluasi selama aktivitas hari yang lalu dan membahas planning pada hari itu ${ }^{30}$.

Untuk mengingatkan para karyawan supaya menjalani hidup sesuai syariah, maka digantungkan pamflet tulisan di dinding ruang makan pekerja 
seperti "Janganah Mencela Makanan Dari

Abu Hurairah ia berkata, Nabi S.A.W tidak pernah mencela makanan sama sekali, kalau beliau berselera maka beliau memakannya dan kalau tidak beliau tinggalkan", "Halal atau Haram? Kejelasan menuju keberkahan”, “Taubat anytime, anyhow, anywhere, more and more, Allah is always ready to accept". Hal ini merupakan kekuatan yang ada pada Syariah Hotel Solo supaya para pekerja termotivasi untuk menjalankan syariah secara benar ${ }^{31}$.

Selain pamflet, poster tentang motivasi, pihak management juga memberikan hadiah bagi karywan yang kinerja dan ibadanya baik. hadiah tersebut berupa uang tunai, barangbarang dan foto karyawan tersebut diletakkan di dinding ruang makan karyawan. Dengan demikian para karyawan akan termotivasi untuk saling berlomba-lomba dalam kebaikan ${ }^{32}$.

Hak para karyawan, adalah menerima gaji. Gaji yang diberikan oleh Syariah Hotel kepada karyawan besarannya melebihi upah minimum regional di Kota Solo, yaitu Rp.1.668.700. Karyawan mendapatkan makan dari hotel tersebut. Selain itu, para karyawan juga mendapatkan asuransi

\footnotetext{
${ }^{31}$ Observasi di Syari'ah Hotel Solo, pada tanggal 13 Oktober 2018

${ }^{32}$ Ibid
}

jiwa dari pihak perusahaan ${ }^{33}$. Dengan keterangan diatas Syariah Hotel Solo di dalam membina para karyawannya dinilai sangat baik, dengan dituaikannya hak dan kewajiban kepada karyawan maka para karyan akan bekerja dengan semakin baik pula.

Dari data diatas dapat dianalisis bahwa Syariah Hotel telah menerapkan maqoshid syariah:

Hifdzu ad din, bahwa fasilitas hotel yang menyediakan; musholla, sajadah, mushaf al Qur'an, pengingat waktu sholat dan hiasan dinding yang bukan becrocak binatang atau manusia.

Selain itu, para karyawan juga diberikan waktu untuk ibadah sholat fardlu maupun sholat sunnah (seperti Sholat Dhuha), karyawan ketika morning meeting, juga membaca ayat al Qur'an dan do'a.

Hifdzu an Nafs, hal ini dapat diidentifikasi dengan adanya asuransi jiwa bagi karyawan dan juga para tamu. Selain itu gaji karyawan yang cukup untuk menghidupi keluarga adalah salah satu daari hifdzu an nafs.

Hifdzu an Nasl, terjaganya kehormatan di Syariah Hotel dapat dilihat dengan karyawan yang memastikan tidak adanya perzinaan di hotel. Para karyawan diberi tausyiyah yang berkala terkait

\footnotetext{
${ }^{33}$ Hasil wawancara dengan kepala bagian General Assistant Manager Syariah Hotel pada tanggal 13 Oktober 2018 pukul 10.15- 11.30.
} 
menjaga kehormatan untuk tetap istiqomah di dalam menjalani hidup yang sesuai syariah.

Hifdzu al 'aql, terjaganya pendidikan dapat dideteksi dari kegiatan yang ada di Syariah Hotel. Seperti pelatihan, tausyiyah, majlis ta'lim yang digelar di Syariah Hotel.

Hifdzu al maal, terjaganya harta dapat dilihat dengan sistem penggajian kepada karyawan. Bahwa para karyawan diberi gaji secara ontime dan melebihi UMR yang ada di solo. Selain itu, jaminan Syariah Hotel atas barang-barang konsumen merupakan salah satu dari hifdzu al maal.

\section{KESIMPULAN}

- Bahwa Syariah Hotel Solo telah menerapkan maqoshid syariah yaitu; hifdzu ad Din, hifdzu an Nafs, hifdzu an Nasl, hifdzu al 'Aql, dan hifdzu al Mal.

- Penelitian ini terbatas pada pengelolaan Syari'ah Hotel Solo.

- Saran, dari penelitian ini, peneliti menyarankan supaya penelitian selanjutnya mengexplore hotel-hotel syariah dengan menggunakan index maqoshid syariah.

\section{DAFTAR PUSTAKA}

Al-Butiy., Muhammad Said Ramdan, 2001, Dawabit al-Maslahat $f \imath$ alSyarīah al-Islamiyyah, Beirut: Muassasah al-Risalah
Alserhan., Baker Ahmad., et al., 2018, 'The transparency of Islamic hotels: "Nice Islam" and the "selforientalizing" of Muslims?', International Journal of Tourism Research, vol. 20, no. 4.

Antonio., Muhammad Syafii, Yulizar D. Sanrego, and Muhammad Taufiq, 2012, 'An Analysis of Islamic Banking Performance: Maqashid Index Implementation in Indonesia and Jordania', Journal of Islamic Finance, vol. 1 , no. 1 .

Ar Raisuni., Ahmad 1995, Nadzoriyyatu Maqoshid inda Imam As Syatibi, Virginia: International of Islamic Thought.

Diskominfo, Pariwisata dan Budaya, edisi VIII, (Solo, Dinas Pariwisata dan Budaya, 2014)

Garibaldi., Roberta, MetthewJ. Stone, Erik Wolf, and Andrea Pozzi, 2017, Wine travel in the United States: A Profile of Wine Travellers and Wine Tours,J. Tourism Management Perspective, 23.

Lahsasna., Ahcene, 2013, Maqashid alShari'ah, Kuala Lumpur, IBFIM

Mohammed., Mustafa Omar Mohammed and Dzuljastri Abdul Razak, 2008, 'The Performance Measures of Islamic Banking Based on th Maqashid Framework e, IIUM International Accounting Conference (INTAC IV), no. June (2008)

Sensus Penduduk 2010. Jakarta, Indonesia: Badan Pusat Statistik. 15 May 2010.

Shiddiq., Ghofar, et al., 2009, Maqashid alsyari'ah, Sultan Agung Vol Xliv No. 120118 Juni - Agustus 2009.

Toriquddin.,Moh, 2014, Teori Maqoshid Syari'ah menurut Imam Syatibi, 
de Jure, Jurnal Syari'ah dan

Hukum, Vol. 06, No. 01

https://www.bps.go.id/pressrelease/2018/10/

01/1476/jumlah-kunjungan-

wisman-ke-indonesia-agustus-

2018-mencapai-1-51-juta-

kunjungan-.html

http://www.tribunnews.com/regional/2019/0

1/05/kronologi-artis-va-

ditangkap-di-hotel-prostitusi-

online-terungkap-dari-laporan-

$\underline{\text { masyarakat }}$

http://www.syariahhotelsolo.com/ 